MATEC Web of Conferences 51, 03005 (2016)

DOI: $10.1051 /$ matecconf/20165103005

(C) Owned by the authors, published by EDP Sciences, 2016

\title{
Analysis of the Effects of Back-stayed Arrangement on the Mechanical Properties of Corbel Shelf
}

\author{
PENG Dou ${ }^{1}$, WANG Zhuan $^{1, a}$ and SHA Cong ${ }^{1}$ \\ ${ }^{1}$ School of Mechanical Engineering, University of Science and Technology Beijing, 100083 Beijing, China
}

\begin{abstract}
With AS/RS corbel shelf as research object, the orthogonal experiment was designed, which is composed of 21 groups of schemes and 3 kinds of load conditions. By using the Rack Computer-Aided FEA System based on SAP84, this paper presents the effects of grounding back-stayed and the ground floor height of back-stayed on the strength, rigidity and stability of corbel shelf under normal load, horizontal load in $\mathrm{X}$ direction and horizontal load in $\mathrm{Y}$ direction. The results show that in all conditions, grounding back-stayed improves the strength and stability of column, and the strength and stability of corbel shelf will be enhanced with the decrease of the ground floor height of back-stayed. This research provides a theoretical basis for the analysis and design of corbel shelf.
\end{abstract}

\section{Introduction}

With the rapid development of the logistics industry, AS/RS corbel shelf has become the main storage equipment of modern logistics center. AS/RS corbel shelf is a unit multi shelf which use the cantilever beam as the loading component [1-2]. The strength and stability of corbel shelf has become the core problem in shelf design, owing to its structure and bearing capacity. As an important component of the AS/RS corbel shelf, back-stayed directly affect shelf stiffness and stability. Therefore, how to arrange the back-stayed has become an urgent problem to be solved.

The current research on AS/RS shelf are mainly focus on three aspects. Firstly, the effects of beam-to-column and column-to-ground semi-rigid connection on the stability of the racks. Freitas et al.[3] studied the effects of connection of beam-to-column on the overall stability of rack. Aajori[4] analyzed the Modal analysis of cold-formed pallet rack structures with semi-rigid connections. Secondly, influence of some parameters on the stability of the shelf. Prabha[5] analyzed the effects of the thickness of the column on the behaviour of Cold-formed steel shelves by using ABAQUS software. Thirdly, evaluation the stiffness and strength of the specific shelf model through the finite element analysis. Affolter[6] studied on the reasons for collapse of a high storage rack. Liu and $\mathrm{Zu}[7]$ studied collapse of shelf when torsion and compression effect on the end of the column at the same time. Jia et al.[8] studied the strength calculation and design method of the AS/RS shelf under the earthquake generated little alternating load. In summary, finite element analysis of AS/RS corbel shelf are mainly focus on the influence of different components connection methods and some parameters on the overall stability of the shelf. But there are few research on the effects of grounding back-stayed

\footnotetext{
${ }^{\mathrm{a}}$ Corresponding author : wzpaper@126.com
} 
and the ground floor height of back-stayed on the mechanical properties of corbel shelf especially under different calculation conditions and loadings at present.

This work analyses the effects of back-stayed arrangement on the mechanical properties of corbel shelf under normal load, horizontal load in $\mathrm{X}$ direction and horizontal load in $\mathrm{Y}$ direction, provides a theoretical basis for the analysis and design of corbel shelf.

\section{Calculation model}

\subsection{Structure}

In this paper, take common beam pallet rack as the research object, the rack is mainly composed of column, corbel, corbel shelf, continuous beam, back-stayed, tie beam, diagonal bracing and row spacer. The shelf scale is 2 row $* 7$ column $* 10$ layer, the total height is $15.5 \mathrm{~m}$, length is $16.8 \mathrm{~m}$, width is $4 \mathrm{~m}$.

Two pallets are placed in each cargo box, the load of each pallet is $1000 \mathrm{~kg}$, and column is divided into two sections. Coordinate system is set as: $\mathrm{X}$ direction on behalf of the rack aisles direction, $\mathrm{Y}$ direction on behalf of the shelf into the deep direction, $\mathrm{Z}$ direction on behalf of shelf height direction. Grounding back-stayed grid structure are shown in Figure 1.
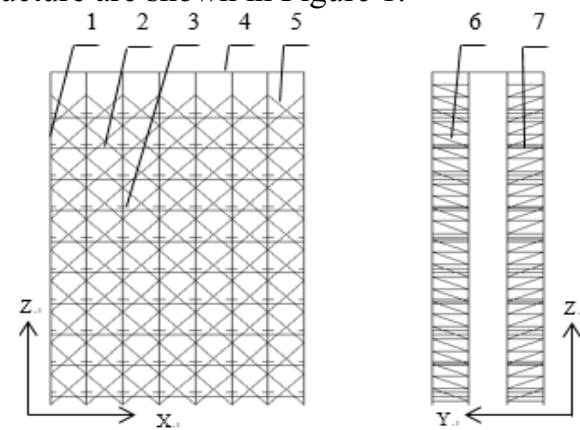

1-Column 2-Continuous beam 3-Corbel 4-Top beam 5-Back-stayed 6-Brace 7-Shelf

Figure 1. The grid structure of grounding back-stayed corbel shelf.

\subsection{Finite element model}

\subsubsection{Element constraint}

In finite element model, column, corbel, corbel shelf, continuous beam and diagonal bracing use frame element, back-stayed uses truss element. All elements are connected rigidly.

\subsubsection{Node constraints and boundary conditions}

All nodes of frame element have six degrees of freedom in SAP84, three translational degrees of freedom and three rotational degrees of freedom. The number 0 means the release of the degrees of freedom and the number 1 means constraints.

All node constraints are released, which can be expressed as $\mathrm{R}=0,0,0,0,0,0$.

The constraints of column-to-ground connected nodes can be expressed as $\mathrm{R}=1,1,1,1,1,1$.

All three-dimensional truss element nodes only has $\mathrm{X}, \mathrm{Y}, \mathrm{Z}$ direction of the translational degrees of freedom without rotational degrees of freedom, which can be expressed as $\mathrm{R}=0,0,0,1,1,1$.

Constrained $\mathrm{Y}$ direction of the translational degrees of freedom due to back-stayed is in the $\mathrm{XOZ}$ plane, and the constraints of its intersection node can be expressed as $\mathrm{R}=0,1,0,1,1,1$. 
Constrained $\mathrm{Z}$ direction of the translational degrees of freedom due to tie beam is in the $\mathrm{XOZ}$ plane, and constraints of its intersection node can be expressed as $\mathrm{R}=0,0,1,1,1,1$.

\subsection{Calculation conditions and loading}

In order to analyze the effect of different load combinations on the mechanical properties of rack, the following three calculation conditions are studied.

Normal condition one: constant load + live load.

Normal condition two: constant load + live load + horizontal load in X direction.

Normal condition three: constant load + live load + horizontal load in Y direction.

In this AS/RS corbel shelf case, its load type, load size and loading position as shown in Table 1.

Table 1. The loads information of corbel shelf.

\begin{tabular}{|c|c|c|c|c|}
\hline $\begin{array}{c}\text { The number } \\
\text { of loads types }\end{array}$ & Load type & Explanation & $\begin{array}{c}\text { Load } \\
\text { size(N) }\end{array}$ & Loading position \\
\hline 1 & Constant load & Weight of the rack & 1864776 & \\
\hline 2 & Vertical impact load & $\begin{array}{c}50 \% \text { of the maximum } \\
\text { static load of goods unit }\end{array}$ & 4900 & $\begin{array}{c}\text { The first row of the first } \\
\text { column top corbel shelf }\end{array}$ \\
\hline 3 & Stacker force & goods reaction force & 822 & Rail crane beam \\
\hline 4 & $\begin{array}{c}\text { horizontal load in X } \\
\text { direction }\end{array}$ & $\begin{array}{c}1.5 \% \text { of all constant loads } \\
\text { and live loads }\end{array}$ & 147 & All joints \\
\hline 5 & $\begin{array}{c}\text { horizontal load in Y } \\
\text { direction }\end{array}$ & $\begin{array}{c}1.5 \% \text { of all constant loads } \\
\text { and live loads }\end{array}$ & 147 & All joints \\
\hline
\end{tabular}

\section{Simulation experiment scheme}

\subsection{Experimental scheme}

According to the calculation model above, the orthogonal experiment was designed, which is composed of 21 groups of connection schemes and 3 kinds of load conditions. Analysis the effects of back-stayed arrangement on the AS/RS corbel shelf stiffness, strength and stability under the different conditions, the simulation experiment schemes are shown in Table 2.

Comparison of scheme A11 and B16, A21 and B26, A31 and B36, we research the effects of grounding back-stayed on the mechanical properties of corbel shelf. In this experiment, the ground floor height of back-stayed is $300 \mathrm{~mm}$.

We study the effects of the ground floor height of back-stayed on the mechanical properties of corbel shelf by all B scheme.

Table 2. Simulation experiment scheme

\begin{tabular}{|c|c|c|c|c|}
\hline Back-stayed caleulation conditions & Conditions 1 & Conditions 2 & Conditions 3 \\
\hline Grounded & $0 \mathrm{~mm}$ & $\mathrm{~A} 11$ & $\mathrm{~A} 21$ & $\mathrm{~A} 31$ \\
\hline \multirow{4}{*}{ Ungrounded } & $50 \mathrm{~mm}$ & $\mathrm{~B} 11$ & $\mathrm{~B} 21$ & $\mathrm{~B} 31$ \\
\cline { 2 - 5 } & $100 \mathrm{~mm}$ & $\mathrm{~B} 12$ & $\mathrm{~B} 22$ & $\mathrm{~B} 32$ \\
\cline { 2 - 5 } & $150 \mathrm{~mm}$ & $\mathrm{~B} 13$ & $\mathrm{~B} 23$ & $\mathrm{~B} 33$ \\
\cline { 2 - 5 } & $200 \mathrm{~mm}$ & $\mathrm{~B} 14$ & $\mathrm{~B} 24$ & $\mathrm{~B} 34$ \\
\cline { 2 - 5 } & $250 \mathrm{~mm}$ & $\mathrm{~B} 15$ & $\mathrm{~B} 25$ & $\mathrm{~B} 35$ \\
\cline { 2 - 5 } & $300 \mathrm{~mm}$ & $\mathrm{~B} 16$ & $\mathrm{~B} 26$ & $\mathrm{~B} 36$ \\
\hline
\end{tabular}




\subsection{Mechanical parameters}

According to the experimental scheme, we use finite element analysis software to modelling, and extract the following mechanical parameters as evaluation indicators:

1) The maximum displacement of nodes (including $X, Y$ and $Z$ directions).

2) The maximum stress of column elements.

3) The stability reduced stress of column elements.

\section{Analysis of experimental results}

This paper selects the maximum displacement of nodes, the maximum stress of column elements and the stability reduced stress of column elements as the research objects, analyses the displacement results of shelves, stress results and the stability results statistically.

\subsection{The effects of grounding back-stayed on the mechanical properties of corbel shelf}

This work analyses the effects of grounding back-stayed on the stiffness, strength and stability of corbel shelf under normal load, horizontal load in X direction and horizontal load in Y direction. The grounding back-stayed experimental results are shown in Table 3.

Table 3. The grounding back-stayed experimental results.

\begin{tabular}{|c|c|c|c|c|c|c|}
\hline \multirow{2}{*}{ Conditions indicator } & \multicolumn{3}{|c|}{$\begin{array}{c}\text { The maximum } \\
\text { displacement }(\mathbf{m m})\end{array}$} & $\begin{array}{c}\text { The maximum } \\
\text { stress (MPa) }\end{array}$ & $\begin{array}{c}\text { The stability } \\
\text { (MPa) }\end{array}$ \\
\cline { 3 - 7 } & $\mathrm{X}$ & $\mathrm{Y}$ & $\mathrm{Z}$ & column & reduced stress \\
\hline \multirow{3}{*}{ Grounded } & Condition 1 & 0.501 & -0.695 & -2.862 & -91.839 & 101.369 \\
\cline { 2 - 7 } & Condition 2 & 1.402 & 0.994 & -2.936 & -107.462 & 116.649 \\
\cline { 2 - 7 } & Condition 3 & 0.63 & 12.46 & -3.364 & -119.005 & 133.204 \\
\hline \multirow{3}{*}{ Ungrounded } & Condition 1 & 0.357 & 0.807 & -2.855 & -115.621 & 117.523 \\
\cline { 2 - 7 } & Condition 2 & 1.438 & 1.084 & -2.928 & -151.866 & 154.424 \\
\cline { 2 - 7 } & Condition 3 & 0.456 & 12.461 & -3.356 & -158.044 & 156.334 \\
\hline \multirow{3}{*}{ Fluctuation } & Condition 1 & $40.34 \%$ & $-13.88 \%$ & $0.25 \%$ & $-20.57 \%$ & $-13.75 \%$ \\
\cline { 2 - 7 } & Condition 2 & $-2.50 \%$ & $-8.30 \%$ & $0.27 \%$ & $-29.24 \%$ & $-24.46 \%$ \\
\cline { 2 - 7 } & Condition 3 & $38.16 \%$ & $-0.01 \%$ & $0.24 \%$ & $-24.70 \%$ & $-14.80 \%$ \\
\hline
\end{tabular}

As can be seen from the data of Table 3:

1)In condition 1 , the grounding back-stayed makes $X$ direction displacement increase about $40 \%$, $\mathrm{Y}$ direction displacement decreases about 13\%, $\mathrm{Z}$ direction displacement has no obvious change, column stress decreases about $20 \%$, stability enhances about $13 \%$.

2) In condition 2, the grounding back-stayed makes $Y$ direction displacement decreases about $8 \%$, $\mathrm{X}$ and $\mathrm{Y}$ direction displacement has no obvious change, column stress decreases about $30 \%$, stability enhances about $25 \%$.

3) In condition 3, the grounding back-stayed makes $X$ direction displacement increase about $40 \%$, $\mathrm{Y}$ and $\mathrm{Z}$ direction displacement has no obvious change, column stress decreases about $23 \%$, stability enhances about $15 \%$.

\subsection{The effects of the ground floor height of back-stayed on the mechanical properties of corbel shelf}


In this work, we analyse the effects of the ground floor height of back-stayed on the stiffness, strength and stability of corbel shelf under the above three conditions. The ground floor height of back-stayed experimental results are shown in Table 4 to 6 .

Table 4. The ground floor height of back-stayed experimental results of condition 1

\begin{tabular}{|c|c|c|c|c|c|}
\hline $\begin{array}{c}\text { Indicator } \\
\text { ground floor height } \\
\text { of back-stayed(mm) }\end{array}$ & \multicolumn{3}{|c|}{$\begin{array}{c}\text { The maximum } \\
\text { displacement(mm) }\end{array}$} & $\begin{array}{c}\text { The maximum } \\
\text { stress (MPa) }\end{array}$ & $\begin{array}{c}\text { The stability } \\
\text { (MPa) }\end{array}$ \\
\cline { 2 - 6 } & $\mathrm{X}$ & $\mathrm{Y}$ & $\mathrm{Z}$ & column & reduced stress \\
\hline 50 & 0.478 & 0.713 & 2.869 & 96.403 & 100.236 \\
\hline 100 & 0.45 & 0.732 & 2.859 & 106.009 & 106.402 \\
\hline 150 & 0.42 & 0.752 & 2.857 & 112.776 & 113.559 \\
\hline 200 & 0.393 & 0.771 & 2.856 & 116.11 & 117.299 \\
\hline 250 & 0.378 & 0.789 & 2.855 & 116.792 & 118.366 \\
\hline 300 & 0.357 & 0.807 & 2.855 & 115.621 & 117.523 \\
\hline The maximum value & 0.478 & 0.807 & 2.869 & 116.792 & 118.366 \\
\hline The minimum value & 0.357 & 0.713 & 2.855 & 96.403 & 100.236 \\
\hline Fluctuation & $33.89 \%$ & $13.18 \%$ & $0.49 \%$ & $21.15 \%$ & $18.09 \%$ \\
\hline
\end{tabular}

Table 5. The ground floor height of back-stayed experimental results of condition 2

\begin{tabular}{|c|c|c|c|c|c|}
\hline \multirow{2}{*}{$\begin{array}{c}\text { Indicator } \\
\text { ground floor height } \\
\text { of back-stayed(mm) }\end{array}$} & \multicolumn{3}{|c|}{$\begin{array}{c}\text { The maximum } \\
\text { displacement(mm) }\end{array}$} & $\begin{array}{c}\text { The maximum } \\
\text { stress (MPa) }\end{array}$ & $\begin{array}{c}\text { The stability } \\
\text { (MPa) }\end{array}$ \\
\cline { 2 - 6 } & $\mathrm{X}$ & $\mathrm{Y}$ & $\mathrm{Z}$ & column & reduced stress \\
\hline 50 & 1.397 & 1.001 & 2.935 & 117.34 & 116.784 \\
\hline 100 & 1.399 & 1.018 & 2.933 & 132.234 & 132.188 \\
\hline 150 & 1.405 & 1.035 & 2.932 & 142.368 & 142.96 \\
\hline 200 & 1.413 & 1.052 & 2.93 & 148.496 & 149.773 \\
\hline 250 & 1.424 & 1.068 & 2.929 & 151.394 & 153.348 \\
\hline 300 & 1.438 & 1.084 & 2.928 & 151.866 & 154.424 \\
\hline The maximum value & 1.438 & 1.084 & 2.935 & 151.866 & 154.424 \\
\hline The minimum value & 1.397 & 1.001 & 2.928 & 117.34 & 116.784 \\
\hline Fluctuation & $2.93 \%$ & $8.29 \%$ & $0.24 \%$ & $29.42 \%$ & $32.23 \%$ \\
\hline
\end{tabular}

Table 6. The ground floor height of back-stayed experimental results of condition 3

\begin{tabular}{|c|c|c|c|c|c|}
\hline $\begin{array}{c}\text { Indicator } \\
\text { ground floor height } \\
\text { of back-stayed(mm) }\end{array}$ & \multicolumn{3}{|c|}{$\begin{array}{c}\text { The maximum } \\
\text { displacement(mm) }\end{array}$} & $\begin{array}{c}\text { The maximum } \\
\text { stress (MPa) }\end{array}$ & $\begin{array}{c}\text { The stability } \\
\text { (MPa) }\end{array}$ \\
\cline { 2 - 6 } & $\mathrm{X}$ & $\mathrm{Y}$ & $\mathrm{Z}$ & column & reduced stress \\
\hline 50 & 0.601 & 12.459 & 3.363 & 139.436 & 137.725 \\
\hline 100 & 0.573 & 12.459 & 3.361 & 149.922 & 148.248 \\
\hline 150 & 0.548 & 12.458 & 3.359 & 155.887 & 154.221 \\
\hline 200 & 0.517 & 12.458 & 3.358 & 158.504 & 156.83 \\
\hline 250 & 0.481 & 12.458 & 3.357 & 158.845 & 157.155 \\
\hline 300 & 0.456 & 12.461 & 3.356 & 158.044 & 156.334 \\
\hline The maximum value & 0.601 & 12.461 & 3.363 & 158.845 & 157.155 \\
\hline The minimum value & 0.456 & 12.458 & 3.356 & 139.436 & 137.725 \\
\hline Fluctuation & $31.80 \%$ & $0.02 \%$ & $0.21 \%$ & $13.92 \%$ & $14.11 \%$ \\
\hline
\end{tabular}




\section{MATEC Web of Conferences}

6:

The effect of the grounding back-stayed on displacement of nodes can be seen from the Table 4 to

1) In condition $1, X$ direction displacement decreases with the increase of the ground floor height of back-stayed, while Y direction displacement increases. The ground floor height of back-stayed has high effect on the $\mathrm{X}$ direction displacement, the fluctuations is $33.89 \%$, Y direction displacement of the second, the fluctuations is $13.18 \%, \mathrm{Z}$ direction displacement of the last, the fluctuations is less than $1 \%$.

2) In condition $2, X$ direction displacement decreases with the increase of the ground floor height of back-stayed, the ground floor height of back-stayed have little effect on the $\mathrm{X}$ direction displacement, which fluctuations is $8.29 \%, \mathrm{Y}$ and $\mathrm{Z}$ direction displacement are less than $2 \%$.

3 ) In condition $3, X$ direction displacement decreases with the increase of the ground floor height of back-stayed. The ground floor height of back-stayed have high effect on X direction displacement, the fluctuations is $31.8 \%$, but have little effect on $\mathrm{Y}$ and $\mathrm{Z}$ direction displacement, their fluctuations are less than $0.5 \%$.

The element stress under different conditions are shown in Figure 2 to 4.

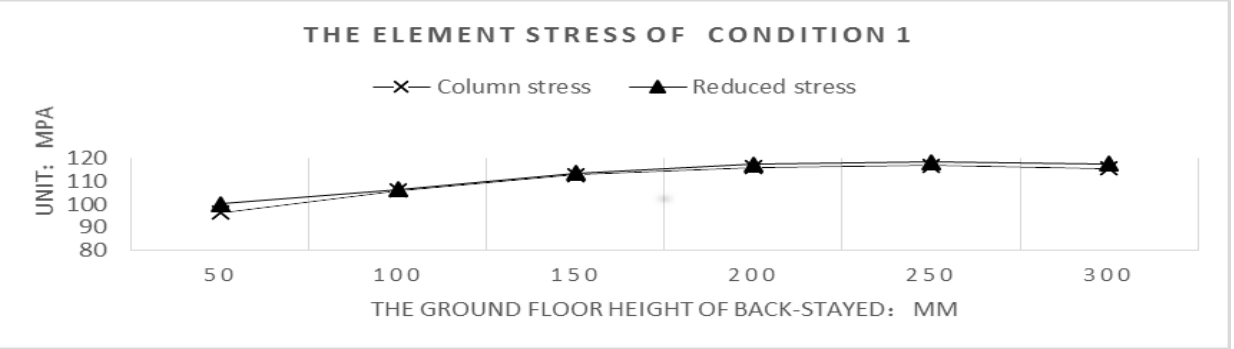

Figure 2. The element stress of condition 1

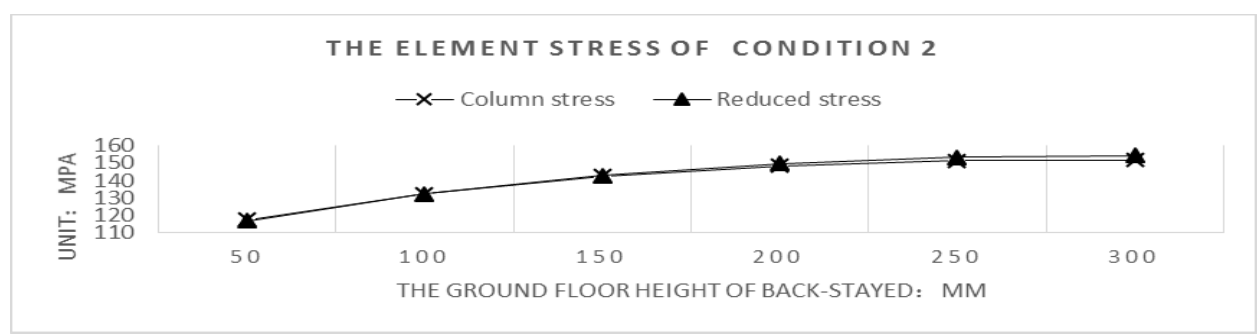

Figure 3. The element stress of condition 2

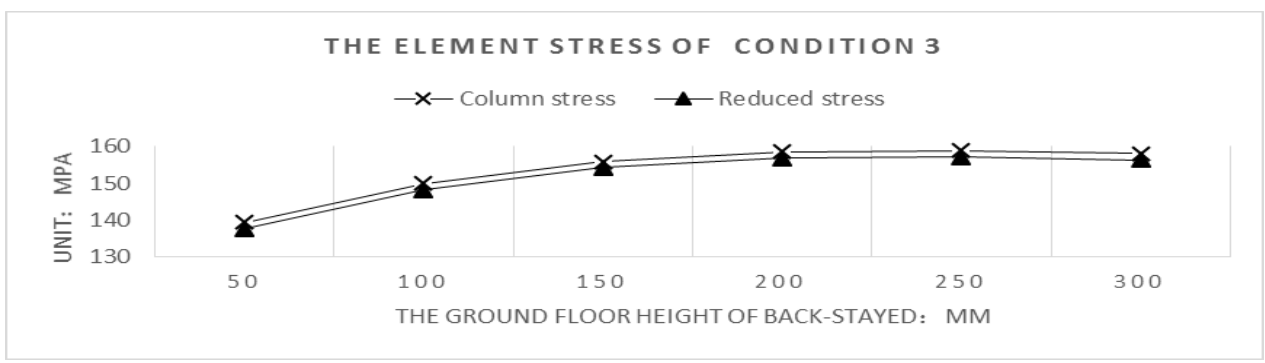

Figure 4. The element stress of condition 3

The effect of the grounding back-stayed on displacement of nodes can be seen from the Figure 2 to 4:

1) In condition 1 and 3, the column strength and stability decreases rapidly with the increase of the ground floor height of back-stayed when the ground floor height of back-stayed is less than or equal to the ground floor height of bracing $(200 \mathrm{~mm})$. The column strength and stability enhances slightly with 
the increase of the ground floor height of back-stayed when the ground floor height of back-stayed is more than the ground floor height of bracing.

2) In condition 2, the column strength and stability enhances with the increase of the ground floor height of back-stayed

\section{Conclusion}

This paper designs and analyses the AS/RS corbel shelf in different back-stayed arrangement by using the FEA software, get the results of displacement and stress under different condition, and draws the following useful conclusions.

1) The grounding back-stayed makes the column strength increases $20 \%$ to $30 \%$ and the stability increases $13 \%$ to $25 \%$, enhances the mechanical properties of corbel shelf greatly.

2) The column strength and stability decreases with the increase rapidly of the ground floor height of back-stayed when the ground floor height of back-stayed is less than or equal to the ground floor height of bracing $(200 \mathrm{~mm})$. The ground floor height of back-stayed have little impact on the column strength and stability when the ground floor height of back-stayed is more than the ground floor height of bracing.

3) The grounding back-stayed and increase of the ground floor height of back-stayed make Xdisplacement increased under the condition 1 and 3, while other conditions have no obvious change.

The above experimental results can provide a theoretical basis for structure optimization and design of this kind goods shelves.

\section{References}

1. GA50018-2002 Technical Code of Cold-Formed Thin-Wall Steel Structures[S].China Association for Engineering Construction Standardization. (2002).

2. Chen Ming, Ma Xiaofei, Zhao Gentian. Seismic behavior of T-shaped joint using cold-formed compound section steel [J]. Engineering Mechanics, 32,184-191 (2015).

3. Arlene M.S. Freitas. Analysis and behavior of steel storage drive-in racks[J]. Thin-Walled Structures ,48,110 - 117 ( 2010)

4. Kamal M. Bajoria. Modal analysis of cold-formed pallet rack structures with semi-rigid connections [J]. Journal of Constructional Steel Research,,66,428-441 (2010)

5. P. Prabha. Evaluation of connection flexibility in cold formed steel racks[J]. Journal of Constructional Steel Research, 66, 863 - 872 (2010)

6. Ch. Affolter. Collapse of a high storage rack [J]. Engineering Failure Analysis, 16,1846-1855 (2009)

7. Liu,Y.Z.\&Zu. Stability and bifurcation of helical equilibrium of a thin elastic rod [J]. Acta Mechanica, 167,29-39 (2004)

8. Jia Zhengxian, Cao Xijing, Liu Changqi. The strength calculation and design of AS/RS rack [J]. Facilities and Equipment, 12,29-54 (2003) 